\title{
Nota preliminar sobre a origem das campinas abertas de areia branca do baixo Rio Negro
}

\author{
Ghillean T. Prance \\ The New York Botonical, Garden, Bronx, \\ New York 10 458, U.S.A. \\ Herbert O. R. Schubart \\ Instituto Nacional de Pesquisas \\ da Amazônia, Manaus
}

No decorrer de uma série de estudos sobre a vegetação das campinas de areia branca da região de Manaus (Anderson et al., 1975; Braga \& Braga, 1975; Carreira, 1976; P. Lisboa, 1975; R. Lisboa, 1975; Prance, 1975), nós pensamos muito sobre a origem da vegetação baixa e rala que caracteriza estas áreas. Várias teses têm sido propostas para esta origem, e nós temos agora alguns dados para substanciar a teoria segundo a qual as áreas abertas são antropogênicas.

As campinas são áreas de vegetação baixa, aberta, escleromórfica sobre areias brancas lixiviadas, classificadas pedologicamente ora como regossolo (Falesi, 1970, 1971) ora como podzol (Klinge, 1965, 1967). Sempre ocorrem áreas abertas de areia nua que às vezes, săo cobertas pela alga cinofícea, Stigonema tomentosum (Kütz) Hieron. A campina é usualmente circundada por um tipo de vegetação florestal também sobre areia branca, que tem sido denominada campinarana (Ducke \& Black, 1954; Lisboa, 1975; Anderson et al., 1975). Esta, por sua vez, é envolvida pela floresta alta de terra-firme sobre latossolo argiloso. Anderson et al. (1975) discutiram detalhadamente a vegetação de uma campina típica e reconheceram uma sucessão da campina aberta para a cam. pina sombreada. A campina aberta foi definida como áreas abertas com ilhas de vegetação, cada ilha com uma área menor do que $1 \mathrm{~m}^{2}$, e sobre a qual a copa perfaz menos do que $50 \%$. A campina sombreada, por sua vez, conduz à campinarana com copa contínua e árvores individuais freqüentemente excedendo a $10 \mathrm{~m}$ de altura. Heyligers (1963) descreveu e discutiu as savanas sobre areia branca do Suriname, onde elas cobrem áreas extensas e têm diversos tipos de vegetação, tanto de floresta como de bosque aberto. 
O objetivo desta comunicação é discutir a razão para a existência de áreas abertas de vegetação na região do baixo rio Negro em controposição às campinaranas sobre areia branca do alto rio Negro. A origem da areia branca da Amazônia também tem sido muito debatida, parecendo, no entanto, bastante claro trataremse de depósitos fluviais quaternários (Sombroek, 1966; P. Landim, comunicação pessoal durante visita de campo) .

Em contraste com a região do baixo rio Negro, outras áreas de areia branca ao norte da América do Sul não apresentam uma tal vegetação aberta. Na região do alto rio Negro, por exemplo, a campinarana é mais alta, mais rica em espécies, e cobre áreas muito maiores e continuas. As campinaranas do alto rio Negro têm sido denominadas freqüentemente de caatingas (veja Ducke \& Black, 1954). A maior riqueza de espécies da campinarana do alto rio Negro pode ser explicada de várias maneiras. A formação mais antiga das areias brancas, as áreas muito maiores e contínuas que elas cobrem, o clima mais úmido com uma estação seca mais curta e menos pronunciada e menor interferência pelo homem pré-colombiano. As áreas de areias brancas da Guiana, denominadas florestas Wallaba, são cobertas por grandes árvores, principalmente Eperua e Ocotea (veja Davis \& Richards, 1933).

Em contraste, as áreas de campinas e campinaranas do baixo rio Negro são "ilhas" pequenas de vegetação sobre areias brancas envolvidas pela floresta pluvial alta. A areia branca oferece um ambiente muito menos favorável para as plantas do que o latossolo argiloso, devido à sua falta de nutrientes minerais e à sua drenagem excessiva (Schubart, $\mathrm{s} / \mathrm{d})$. O número de espécies vegetais capazes de suportar os fatores limitantes da areia branca é consideravelmente menor do que nos outros tipos de solo. Muitas espécies da areia branca são endêmicas a estas areias, e não ocorrem nas regiões de latossolo. Conseqüentemente, as pequenas manchas isoladas ou ilhas de areia branca dependem da chegada das espécies características de areia branca pela dispersão sobbre a floresta alta circundante. Um estudo de uma campina por Macedo (1975) mostrou que $75,7 \%$ das espécies têm um óbvio potencial para dispersão à longa distância (por exemplo, $13.5 \%$ de dispersão pelo vento, e $59,5 \%$ de dispersão por pássaros). Devido à sua natureza isolada, as areias brancas do baixo rio Negro têm uma flora muito reduzida em comparaçäo com o alto rio Negro.

A existência de campinarana em todas as áreas de campinas estudadas indica que as espécies deste tipo de floresta ocorrem na região do baixo rio Negro. Nós nos perguntamos, muitas vezes, por que as campinas abertas também são tão comuns no baixo rio Negro? Parece-nos que estas áreas foram uma vez derrubadas e se encontram agora em um processo de sucessão para a campinarana. Devido aos fatores ambientais limitantes, este processo de sucessão é extremamente lento, como é usualmente o caso quanto existe uma tensão ambiental. No caso da areia branca, este fator limitante é provavelmente uma combinação da falta de nutrientes e do solo bem drenado, que se torna extremamente seco durante curtos períodos na estação seca.

Nossa evidência para a derrubada pelo homem nas áreas de campinas abertas é baseada em um estudo de quatro campinas: a campina da reserva do INPA-SUFRAMA, no $\mathrm{Km} 62$ da estrada Manaus-Boa Vista, a campina próxima ao rio Cuieiras, logo abaixo da foz do rio Branquinho, a campina do Ramal da Terra Preta, proxima à Cacau Pirera, e a campina do Leăo, no $\mathrm{Km} 18$ da estrada Manaus-Boa Vista.

Em todas as quatro campinas estudadas, nós encontramos uma abundância de cacos de cerâmica indígena. Esta cerâmica foi identificada pelo Dr. Mário F. Simões como pertencente à subtradição Guarita. Material desta subtradição proveniente de vários sítios tem sido datado pelo método do $\mathrm{C}_{14}$, com os seguintes resultados:

$$
\begin{aligned}
& \text { Sítio Canteiro - Iha de Terra Nova - } \\
& \text { A.D. } 750 \pm 80 \\
& \text { Sítio Santa Rosa - Rio Apuaú } \\
& \text { A.D. } 825 \pm 90 \\
& \text { Sítio Coari - Coari } \\
& \text { A.D. } 1150 \pm 41
\end{aligned}
$$
cação pessoal) . 
A areia, na campina do Cuieiras, contém muito carväo vegetal a uma profundidade de cerca de $20 \mathrm{~cm}$ abaixo da superfície. Nós conseguimos coletar amostras deste carvão para datação por radiocarbono. Os resultados obtidos mostraram que este carvão formou-se há $1.150 \pm 30$ anos antes do presente. Isto dataria o carvão no ano 800 A.D., ou seja na época da subtradição Guarita.

A campina do Cacau Pirera, também contém muito carvão à mesma profundidade apro. ximadamente.

A ocorrência deste carvão e dos cacos de carâmica indicaria que os índios derrubaram as campinaranas sobre areia branca por volta do ano 800 A.D. Tanto o sítio do Cuieiras como o sítio de Cacau Pirera têm uma área de "terra preta" nas proximidades, um curioso solo escuro de origem antropogênica, com elevada fertilidade (veja Sombroek, 1966; Falesi, 1970). Este solo é também característico de áreas arenosas ocupadas por índios. Este solo mais rico é coberto por campinarana ao invés de campina aberta. Nossa evidência mostra que os indios derrubaram as campinaranas sobre areia branca, embora provavelmente não tenham cultivado toda a área. As áreas de "terra preta" ocorrem onde eles cultivaram. As áreas de areia branca foram possivelmente usadas para moradia, devido ao ambiente mais agradável.

As areias brancas eram provavelmente cobertas por campinaranas antes de sua ocupação pelos indios da sutradição Guarita. Desde que estas áreas foram abandonadas pelos indios, talvez em torno de 1200 A.D., o processo de sucessão vem correndo. Ele é extremamente lento devido aos fatores limitantes edáficos e nutricionais, porém, mesmo assim está ocorrendo. Sucessão lenta em direção ao climax é um fenômeno peculiar a áreas com algum fator limitante como ocorrem na região temperada do norte após a recessão do gelo nas Eras Glaciais.

\section{AGRADECIMENTOS}

Nós ficamos gratos ao Dr. Th. van der Hammen por conseguir a datação do carvão vegetal no Laboratório de $\mathrm{C}_{14}$ de Groningen, e ao
Dr. Mário F. Simões por estudar os fragmentos de cerâmica coletados nas campinas. Agradecemos a Anthony Anderson por fornecer um levantamento básico da vegetação de campina. O trabalho de campo foi realizado enquanto Ghillean T. Prance usufruia $\alpha$ auxílio INT $75-$ 19282 da National Science Foundation, à qual expressa seus agradecimentos.

\section{SUMMARY}

The origins of the open areas of white sand campinas of the lower rio Negro is discussed. Campinas are compared with the denser campina forests or caatingas of the upper rio Negro. It is concluded that the campinas are areas of white sand forest cleared by Indians. Evidence from pottery shards and radiocarbon dating of charcoal deposited in the soil demonstrates that the campinas were occupied by Indians of the Guarita subtradition around 800 A.D. The open campina areas show a gradual sucession to more closed type of campina to campina forest, the climax on the white sand, Recolonization after Indian clearing is extremely slow on white sand because of limiting factors such as nutrients and excessive drainage in the dry season.

\section{BIBLIOGRAFIA CITADA}

Anderson, A.B.; Prance, G.T. \& Albuquerque, B.W. DE 1975 - Estudos sobre a vegetação das Campinas Amazônicas III. A vegetação lenhosa da Campina da Reserva Biológica INPA-SUFRAMA (Manaus-Caracarai, $\mathrm{km}$ 62) Acta Amazonica, 5(3) : 225-246.

BRAGA, M.N. \& BRAGA, P.I.S.

1975 - Estudos sobre a vegetação das Campi. nas Amazônicas IV. Estudos ecológi cos na Campina da Reserva Biológica INPA-SUFRAMA (Manaus-Caracaraí, $\mathrm{Km}$ 62). Acta Amazonica, 5(3):247-260.

CARREIRA, L.M.M.

1976 - Morfologia polínica de plantas lenhosas da campina. Acta Amazonica, 6(3): 247-269

DAvis, T.A.W. \& RichaRdS, P.W.

1933 - The vegetation of Moraballi Creek, British Guiana: an ecological study of a limites area of tropical rain forest. Jour. Ecol., $21: 360-384$.

DUCKE, A. \& BLACK, G.A.

1954 - Notas sobre a fitogeografia da Amazónia Brasileira. Bol. Técn. do IAN, Be. lém, $29: 1-62$. 
FALESI, I.C.

1970 - Os solos da área Cacau-Pirera-Manacapuru, Inst. Pesq. Exp. Agrop. do Norte Série: Solos da Amazônia, 2(3): 1-198.

1971 - Solos do distrito agropecuário da SUFrama. Inst. Pesq. Exp. Agrop. Amaz. Occ. Série : Solos, 1(1) : 1-99.

HeYLigers, P.C.

1963 - Vegetation and soil of a white sand savanna in Suriname. N.V. NoordHollandsde Vitgevers Maatschappig-Amsterdam. $148 \mathrm{pp}$.

KLINGE, $\mathrm{H}$.

1965 - Podzol soil in the Amazon basin. Jour. Soil Sci., $16: 96-103$.

1967 - Podzol solls: a source of blackwater rivers in Amazonia. Atas do Simpósio sobre a Biota Amazônica, Limnologia, Rio de Janeiro, $3: 117-125$.

LISBOA, P.L.

1975 - Estudos sobre a vegetação das Campinas Amazônicas - II. Observaçōes gerais e revisāo bibliográfica sobre as campinas amazônicas de areia branca. Acta Amazonica, 5(3): 211-223.
LISBOA, R.

1976 - Estudos sobre a vegetação das camplnas amazônicas V. Brioecologia de uma campina amazônica. Acta Amazonica, $6(2): 171-191$

MACEDO, M.

1976 - Dispersão de plantas lenhosas de uma campina Amazônica. Tese, INPA e Fundação Universidade do Amazonas.

Prance, G.T.

1975 - Estudos sobre a vegetação das Campinas Amazônicas I, Introduçāo a uma série de publicaçōes sobre a vegetação das Campinas Amazônicas. Acta Amazonica, 5(2): 207-209.

SChUBart, H.O.R,

s/d - Ecossistemas amazônicos produtores de água preta: um modelo (em preparação) .

SOMBROEK, W.G

1966 - Amazon Soils. A reconnaissance of the soils of the Brazilian Amazon region. Centre for Agricultural Publications and Documentation, Wageningen, 1966. 